\title{
A HISTORY MAP STUDY IN BRITISH COLUMBIA
}

\author{
By E. H. Garman and P. M. BarR
}

Research Division, British Columbia Forest Service

\section{INTRODUCTION.}

$\mathrm{T}$

HE most important silvicultural problem facing British Columbia foresters is the regeneration of logged-off lands on Vancouver Island and the adjacent mainland. The forests in this region, consisting mainly of Douglas Fir, Hemlock, and Western Red Cedar, furnish almost half of the lumber cut in Canada each year, and they occupy sites of remarkable productivity. Most of the cutover lands are useful only for forest purposes, and because of their accessibility and capacity for producing valuable timber crops on short rotations, they should be the first areas in British Columbia to be placed under intensive forest management.

\section{NATURAL REGENERATION.}

The conditions of soil and climate in this region combine with the silvical characteristics of the native species to make natural regeneration rapid and prolific. The small blocks of cutover land, typical of logging operations on the west coast prior to 1915 , have in most cases become well stocked with thrifty stands of second-growth, and any farm land or pastures which may lie unworked for more than a very few years are likely to be invaded by the rapid-growing conifers which are everywhere abundant.

During the past fifteen years, however, remarkable changes have taken place in methods of logging in the Douglas Fir region, largely destroying the efficiency of natural regeneration, and producing a serious silvicultural problem. In the earliest woods operations, when logs were hauled by horses or oxen, the cuttings were of a definitely selective type, only the largest and best trees being felled. Many mature trees, defective or misshapen, were left standing, and in hauling the logs from the woods little damage was done to the smaller trees and saplings. As a result, a considerable amount of advance growth remained to partially restock the cutover area, and there was no lack of seed trees to regenerate the openings. Since the logging slash consisted of little more than the tops and branches of felled trees, there was no serious accumulation of inflammable debris, and the remaining trees and undergrowth prevented the litter and slash from drying rapidly during the spring and summer.

With the introduction of steam machinery, and more intensive cutting methods, a larger proportion of the timber was felled, and much of the underwood was knocked down in skidding out the logs. So long as the logs were 
hauled along the surface of the ground, however, by means of slow and mod. erately-powered machines, most of the larger trees not felled for removal were uninjured, and remained to insure an abundant source of seed for second-growth. The fire danger became more acute under the new conditions, but when a fire did occur it was usually restricted to the comparatively small area which had been logged during the preceding years. On burns of this type many of the standing trees would survive the fire, at least to live and produce seed for one or more seasons, and in any case an abundant seed supply existed in the stands of uncut timber adjacent to the burned areas.

With the development of the high-lead and skyline systems of logging, during the war and in the years following, different conditions have been produced. Closer utilization is practised and in skidding the logs by highspeed heavy machinery practically every living tree not selected for cutting is knocked down, together with dead trees, and an enormous amount of debris accumulates, fully exposed to sun and wind, and which during the summer can become exceedingly inflammable. Under such conditions disastrous fires are inevitable. These destroy not only any fresh tree seeds on the ground but also the few surviving small or broken trees which are the only means of producing seed within the boundaries of the cutover areas. Modern log. ging in the Fir region is also conducted on such a large scale and at such high speed that the operations of a single company may cover several hundred acres during a year. A fire, sweeping through the accumulated cuttings of several years, under these conditions, results in incomplete devastation, with no reproduction or any supply of tree seed upon the burned land, and the

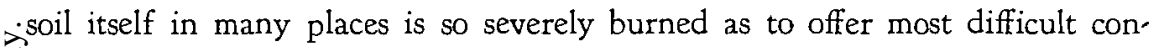
zditions for seedling germination or survival.

. The timber surrounding large burns of this nature is the only source of Ë E्ठ̃ quantities up to only one-quarter of a mile (1), and much of the burned land $\Xi$ is too far removed from the marginal stands to receive any seed from that Do ofsource. There would be a possibility of at least partial restocking if the II slash were burned promptly at the end of each summer, and if the marginal timber produced a heavy crop of seed every autumn. Unfortunately, neither of these conditions exist. With more intensive forestry practice it may be possible to have regular annual slash-burning, as a protective measure, but studies (2) have shown that seed production is erratic, good crops occurring

1. Pickford, A. E., 1929. Studies of Seed Dissemination in British Columbia. For. Chron., Vol. 5, No. 4, 8-16.

2. B. C. Forest Service. Studies of Annual Crops of Tree Seed. Unpublished data. 
only at intervals of several years. In the intervening seasons the small quantity of seed produced is further reduced by insect damage.

The establishment of seedlings on burned land of the type referred to above is more difficult and uncertain than on soil which has been lightly burned over limited areas. The exceedingly hot fire, produced by dense slash, consumes almost the entire organic content of the soil and this change greatly reduces its moisture holding capacity. Such burned soils become so dry in summer that young seedlings cannot survive. Further losses may be caused by high surface temperatures, produced by direct exposure of the mineral soil to the sun. On steep slopes, considerable erosion and sliding of the loose soil will occur during heavy rains, destroying any seedlings established during the previous year. In addition to these losses by physical factors, young seedlings are subject to attack by damping-off fungi, or damage by rodents or insects. Browsing by deer is also a common cause of damage and in sparsely restocked stands such a large proportion of the young trees may be injured in this way that regeneration is seriously retarded.

It should not be concluded that slash must be burned in all cases. On many areas an advance growth of hemlock is present, and where logging has been carried on after a heavy seed-fall, dense stands of young conifers may germinate among the brush and debris during the following spring and summer. Both these types of young stands are likely to survive and grow thrift. ily. If such regeneration is destroyed in a slash fire or accidental burn it may be difficult or impossible to re-establish a coniferous cover promptly by natural means. (3.)

\section{GENERAL PLAN OF STUDY.}

The British Columbia Forest Service is making an organized effort to study the general problem outlined above. Preliminary surveys were first undertaken, which indicated the main features of the situation, and most of the separate phases of the problem were later placed under study by means of permanent experimental plots. It has also become desirable to study the changes occurring on more extensive areas than small plots, and to provide blocks of cutover land, whose past history is known, for future experimental needs.

For this purpose ten logging operations, including about 87,000 acres, have been selected and brought under periodic observation and study. Due to their diverse location, these ten tracts are typical of the conditions existing on most of the land which has been logged in the Douglas Fir type during the past fifteen years. Each of the selected areas consists of a patchwork of

3. Pickford, A. E., 1930. Causes of mortality in young seedlings of Douglas Fir and associated species. (MS. in course of publication.) 
cuttings, burns, inaccessible or unmerchantable timber, and, in some cases, stands of merchantable timber not yet logged. Three main forest types are represented, the pure Douglas Fir type of Southern Vancouver Island and some parts of the Lower Mainland, the Fir-Cedar-Hemlock type, and the Cedar-Hemlock forests of Northern Vancouver Island and the adjacent mainland, which extend beyond the commercial range of Douglas Fir.

\section{DESCRIPTION OF HISTORY-MAP AREAS.}

Most of the land included in the study-areas has been logged by the highlead or skidder methods, although ground-lead machinery was used on some of the older cuttings. Under each of the former methods the effect of logging has been to remove or destroy practically all the trees, few or none being left to act as seed trees. In most cases the slash has been burned in the autumn or spring for the purpose of reducing the fire hazard, or by accidental fires which usually occurred during July and August. In any kind of fire, the seed trees which may have remained after logging have been destroyed, together with any viable seed on the ground. Fires during the summer are likely to consume the humus layers of the soil, and the mineral soil itself may be affected. Slash burning, in the fall or spring, may partially destroy the humus, but during these seasons the fires are less intense, and damage to the soil is unlikely to be nearly so severe as that caused by uncontrolled fires burning in dry slash in the heat of summer.

Of the 87,000 acres of land covered by the study, 48,500 acres have been burned, 20,500 acres bear unburned slash, and 18,000 acres, containing unproductive sites or fire-killed timber, have been excluded from intensive examination.

\section{FIELD METHODS.}

As the first step in the field work, plans were obtained from operators showing railway grades and spar trees. These features were convenient for the main ties of the reproduction survey. Operators were usually able to furnish other important information, such as details of the history of their properties, dates of logging on specific areas, amount of timber cut from each type, and the occurrence of fires.

The first main purpose of the field work was to delineate the unit-areas of uniform history and condition, consisting usually of adjacent settings logged from the beginning of one growing season to the beginning of the next. Other unit-areas consisted of blocks of standing timber, or non-productive land. Following the definition of these main subdivisions of each property, plots were located in each unit-area for the purpose of studying conditions of regeneration, and to check information furnished by the operator. These plots were each 6.6 feet wide and 66 feet long, and were laid down, end to end, in continuous strips, which were usually run from a point near a rail- 
way grade. A reference stake was set on the grade in each case, as a means of identification for future examinations. At the end of the 1929 season 1,750 plots had been located and examined.

Maps were prepared, showing the location of unit-areas, plots, land surveys, railway grades, seed-trees and the position and direction of photographs. The seedlings were tallied in each plot by one-foot height classes for trees less than 16 feet high, and by diameter classes for larger trees, correlated with age by taking the ages of sample seedlings. At the end of each fifth plot a quadrat, 6.6 feet square, was examined to learn the proportions of the ground surface occupied by plant cover, debris, and bare soil. An estimate was also made on this quadrat of the relative abundance of each species of plant. For each series of five plots general notes were taken of topography, soil, vegetative cover, slash disposal, and logging history.

OFFICE RECORDS.

At the close of the season the field maps were redrawn in permanent form, two copies being made for each area, one to serve as a field copy for future examinations, and the other as an office record, to which new information could be added each year. To facilitate analysis of the statistical data, summaries were made for each operation and type, giving the following information:--

Plot number

Number of seedlings, by species

Dates of logging

Seed supply

Distance from seed trees

Aspect

Ground cover

Miscellaneous notes.

By means of the maps and summaries it is possible to compare the several study-areas, and from the remeasurements of any single area to note the changes which may occur from year to year.

Tables I, II, and III herewith, present a general summary of the conditions of natural regeneration, based on the notes of the entire group of areas covered by the history maps.

RESULTS.

The main purpose of the undertaking is to develop a group of records, over a period of years, which will eventually give a broad picture of silvicultural conditions in the Douglas Fir region and the development of forest cover on logged-off land, rather than to secure immediate results. However, it is of interest to consider the information which is already available.

It is not known at present, for even any one type or condition, what 


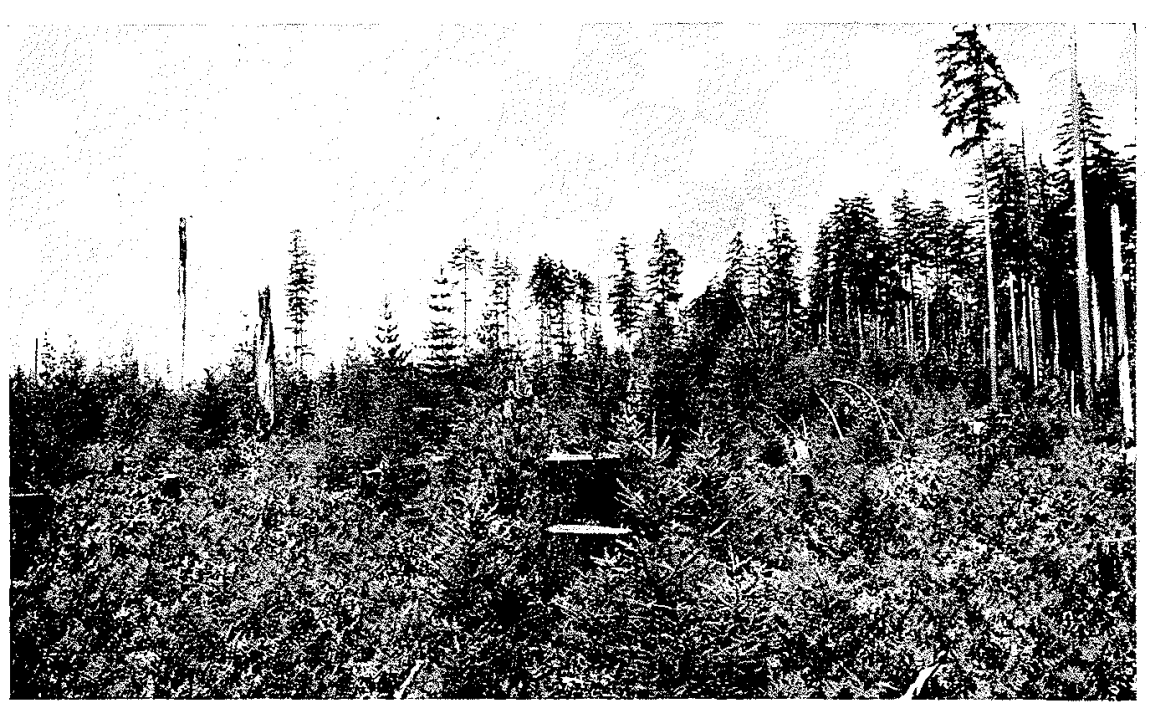

The Seed Trees Provided Seed after Two Burns Here.

Douglas Fir-White Pine-Hemlock seedlings in foreground followed a fire 17 years ago which left the remnant shown, now 30 years old. Note rapid height growth of White Pine. Herbaceous cover is bracken. Poor site, Douglas Fir type, Central Vancouver Island.

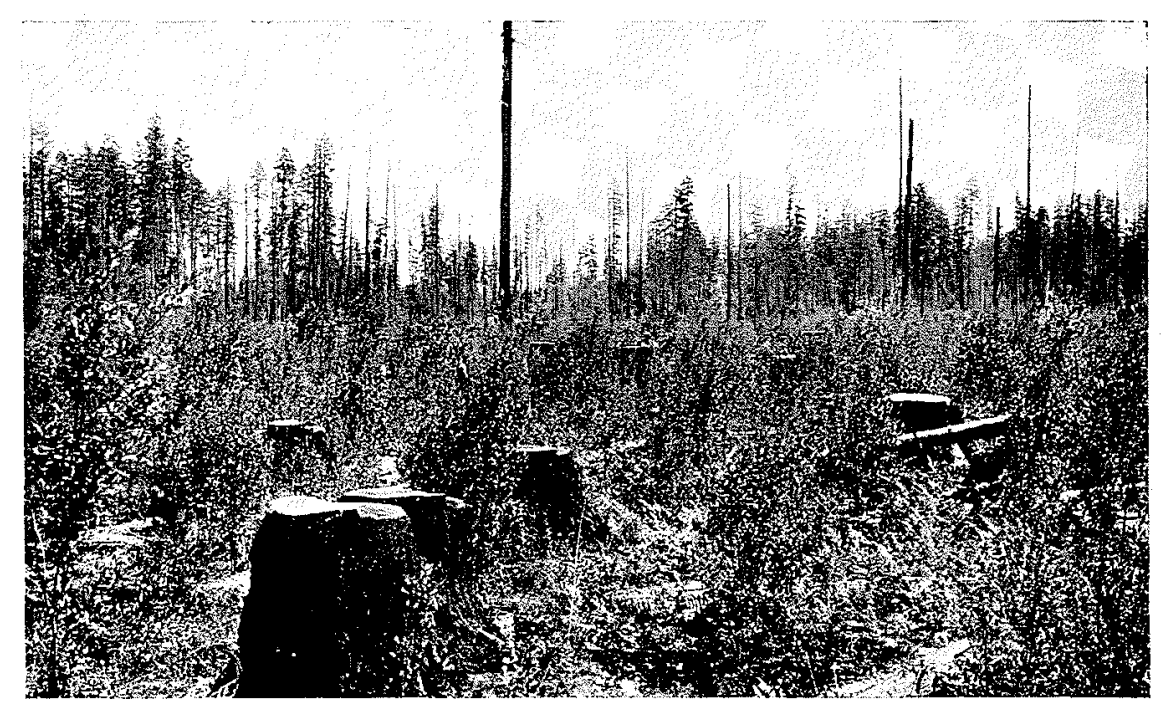

History Map Plot in willow-lawkweed ground cover type, six years after burn. 140 Douglas Fir seedlings per acre. Sandy soil, Douglas Fir type, Central Vancouver Island. Note tape marking centre-line of plot. 


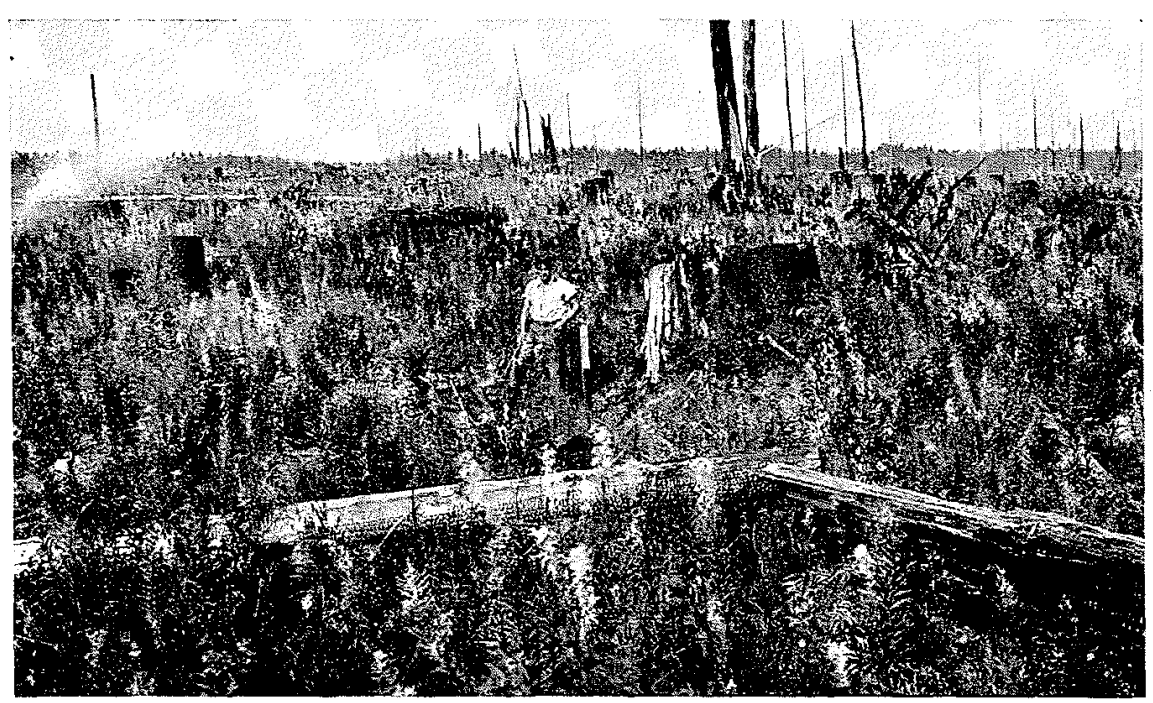

History Map Plot in Douglas Fir type 3 years after being burned during logging. Medium density fireweed. 20 Cedar-Hemlock seedlings per acre. Central Vancouver Island.

density of young trees is necessary for adequate restocking. As the distribution of plots shows a decrease from the lowest reproduction class to the highest, there is consequently a wide dispersion from the mean. This rather large variation in density is indicated by the standard deviation of 2,212 seedlings per acre from the mcan of 1,430 seedlings per acre for the 1,623 plots used in the tables. The median plot of the frequency distribution for all plots has a value of 650 seedlings per acre, which means that on fifty per cent of all the plots less than this density of seedlings is established. It is doubtful if this number of seedlings per acre is a satisfactory minimum. Therefore, it may be safely stated that the majority of the plots are inadequately restocked at the present time.

The density of herbaceous and shrubby growth is an important factor. Fireweed (Epilobium angustifolium) is usually the first species to occupy most logged sites. When very little plant cover is present, young seedlings suffer from over-exposure to insolation and drought, and many are killed from this cause during the early months of the first two growing seasons. On the other hand, where seed trees are available, the very dense fireweed of good sites and the dense fireweed-salal of poor sites will prevent germination of coniferous species. Also, on sites which tend to becone brushy a dense growth of salmonberry (Rubus spectabilis) and huckleberry (Vaccinium ovatifolium). will prevent the establishment of conifers for many years if the regeneration does not become well established within five years of logging. 
Hemlock and cedar are more prolific seed producers than Douglas Fir, and when these species occur in mixture with fir in the timber adjacent to cutover lands, regeneration at first is likely to consist mainly of these two species. However, Douglas Fir has a greater ability to survive, particularly on burned land and exposed sites. The composition of the new cover on burns differs widely, the proportion of fir being as high as 75 per cent in study-areas on southern Vancouver Island, and as low as 1 per cent in the northern part of its range, the remainder of the regeneration consisting of hemlock and cedar, in varying proportions, with occasionally White Pine or balsam. When averaged over the entire region, fir, cedar, and hemlock occur in nearly equal proportions on logged-off land that has been burned.

Fir is the most important species in the mature forests being cut at present, and over most of the operations covered by the study, this species has formed the main part of the stand, by volume. In most cases, however, there is a smaller proportion of fir in the regeneration than in the original forest. It may be concluded that the composition of the second growth is influenced primarily by the amount of seed produced by each tree species in the marginal timber, modified by soil conditions and weed cover, and that it varies with age. The proportion of fir is much greater on burned cuttings than on unburned land, while that of hemlock is very much less. Approximately twothirds of the land under observation has been burned one or more times.

Fire is probably the most important factor in the natural regeneration of the region. Reference has been made already to the bad effects of slashburning upon forest soils, and these effects are intensified by the repeated fires which sometimes run over old cuttings at intervals of a few years. Under such conditions no natural regeneration can be expected.

Burns immediately after logging, with subsequent protection against fire, probably will not lengthen the regeneration period, since an adequate supply of seed will be furnished by nearby marginal timber. If the seed crop has been an entire failure, adjacent lands should not be logged until the burned areas have restocked.

\section{SUMMARY AND CONCLUSIONS.}

The British Columbia Forest Service is making a study of the problem of natural regeneration following logging operations in the Douglas Fir region.

The main features affecting the regeneration are:

1. Seed supply is dependent on marginal timber often far removed from seed beds, and having erratic crops of cones.

2. Seedlings are damaged by biotic and physical factors.

3. Fires frequently occur in the slash.

Maps were made in ten representative logging operations to record the conditions existing on large units of cut-over lands, supplemented by plots 
established to record the reproduction and ground cover. The study has covered 87,000 acres of logged land, revealing that 48,500 acres have been burned after logging and that 20,500 acres of slash have remained unburned. On this area 1,750 plots, each $1 / 100$ acre, have been established.

The first examinations show that 45 per cent of all the plots have less than five hundred seedlings per acre.

The composition of the reproduction varies under the influence of seed supply modified by site conditions. The density of new stands may be affected by the condition of the ground cover which may be either too dense, or insufficient to provide protection. The Douglas Fir on burns varies from 75 per cent on southern Vancouver Island to only 1 per cent in the northern part of its range. Over the whole region fir, hemlock, and cedar occur in nearly equal proportions on burns, although hemlock and cedar are often the main species of the marginal stands; Douglas Fir comprises 26 per cent. of the reproduction on burns and 12 per cent. on unburned cuttings, the proportion of hemlock being considerably less after fires.

The purpose of this study, to show the effect of the changes occurring after logging, will become more evident when the data from re-measurements of the plots over a period of years is analyzed and compared with the information gained from the first survey. Initial measurements are being extended in the logging operations already being studied, to increase the amount of data on which future results will be based.

It is evident at this stage that over half of all the cut-over land in the operations studied is insufficiently stocked to provide a new crop, a condition largely due to a lack of seed supply as a result of logging methods and poor seed crops.

The study shows that fire is an important factor affecting composition of the new stands, and that herbaceous cover often affects the density of the second growth, at least during the early stages of regeneration. 
TABLE 1.

DISTRIBUTION OF PLOTS BY REPRODUCTION CLASSES

\author{
Number \\ of Seedlings \\ per Acre
}

0 and less than 500
500 " " " 1000

1000 " " " 2000

2000 " " " " 3000

3000 " " "

4000 " " " 5000

Over 5000

Total number of plots examined

Number of Plots
Logged Logged Total
and Burned Only
495

495
154

134

67

36

23

60

969
Proportion

in each

Class per cent

729

271

256

132

69

42

124

$654 \quad 1623^{*}$
45

17

16

8

4

3

7

100

*Does not include 127 plots logged or burned in 1928.

\section{TABLE 3.}

DISTRIBUTION OF SEEDLINGS BY SPECIES

Percentage of Seedlings on all plots in each type of Site.

Douglas Fir

Western Hemlock

Western Red Cedar

Other species

Total

Basis: No. of

Seedlings

Logged \& Burned

$$
26 \%
$$

38

33

3

$100 \%$

12,411

All

Logged Iand

$12 \%$

50

33

5

$100 \%$

13,345

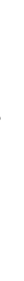


TABLE 2:

PERCENTAGE DISTRIBUTION OF PLOTS BY REPRODUCTION CLASSES IN EACH DISTRICT

\begin{tabular}{|c|c|c|c|c|c|c|c|c|c|c|c|c|c|c|c|c|c|c|}
\hline \multirow{4}{*}{\multicolumn{5}{|c|}{$\begin{array}{l}\text { Number } \\
\text { of Seedlings } \\
\text { per Acre }\end{array}$}} & \multicolumn{14}{|c|}{ LOCATION OF AREAS EXAMINED } \\
\hline & & & & & \multicolumn{7}{|c|}{ Logged and Burned } & \multicolumn{7}{|c|}{ Logged Only } \\
\hline & & & & & 营 & 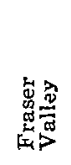 & 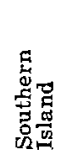 & 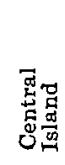 & 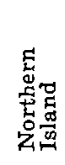 & 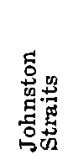 & 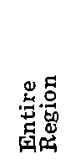 & 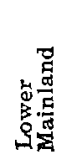 & 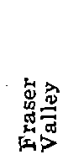 & 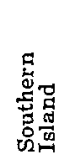 & 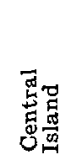 & 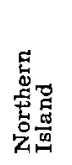 & 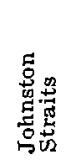 & 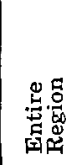 \\
\hline & & & & & \multicolumn{14}{|c|}{ Proportion of Plots in Each Class, Percent } \\
\hline 0 & and & les: & than & 500 & 30 & 42 & 48 & 74 & 46 & \multirow{7}{*}{ 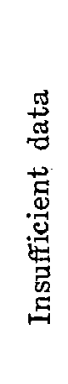 } & 51 & 22 & 64 & \multirow{7}{*}{ 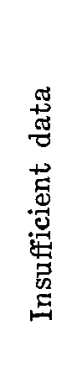 } & 41 & 22 & \multirow{7}{*}{ 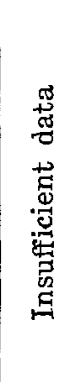 } & 36 \\
\hline 500 & “ & “ & & 1000 & 16 & 21 & 21 & 7 & 19 & & 16 & 17 & 17 & & 17 & 27 & & 18 \\
\hline 1000 & “ & & & 2000 & 20 & 16 & 19 & 7 & 10 & & 14 & 22 & 14 & & 13 & 22 & & 19 \\
\hline 2000 & “ & & & 3000 & 15 & 7 & 6 & 4 & 5 & & 7 & 14 & 3 & & 8 & 10 & & 10 \\
\hline 3000 & “ & & & 4000 & 7 & 5 & 3 & 2 & 2 & & 4 & 7 & 0 & & 6 & 3 & & 5 \\
\hline 4000 & & “ & $“$ & 5000 & 4 & 1 & 1 & 3 & 3 & & 2 & 3 & 1 & & 3 & 7 & & 3 \\
\hline \multicolumn{5}{|c|}{ Over 5000} & 8 & 8 & 2 & 3 & 15 & & 6 & 15 & 1 & & 12 & 9 & & 9 \\
\hline \multicolumn{5}{|c|}{ No. of Plots examined } & 158 & 210 & 175 & 300 & 110 & 16 & 969 & 271 & 149 & 9 & 130 & 40 & ${ }^{*} 55$ & 654 \\
\hline
\end{tabular}

